\title{
Национальная диктатура \\ или парламентская демократия: \\ к вопросу об альтернативах развития \\ Германии в годы Веймарской республики (на примере Пангерманского союза)
}

\begin{abstract}
Аннотаиия. В статье речь идет о пангерманских конщепииях государственной власти и государственного устройства Германии после Нолброской револючии 1918 г. В них лидерами Пангерманского союза (Г. Класс, Л. фон Фитингхоф-Шеель, А. Мюллер) была обоснована необходимость реформирования государства по приниипу диктатуры. Идея диктатуры одними связывалась с единоличным правлением вождя (Класс), другими - снародным представительством, выбираемым из числа «полноченных» патриотов Германии (Фитингхоф-Шеель). Подиеркивается преемственность пангерманизма и наиионал-соииализма. В истории пангерманизма веймарский период занимает важное место. Это связано с тем, ито в эпоху веймарской парламентской демократии во взглядах, политическом мышлении и характере действий пангерманщев произошли важные изменения, направленные в сторону их радикализаиии. Несмотря на резкость высказываний в адрес органов государственной власти, пангерманиы вынуждены были признать за ними реальную политическую власть, как и отсутствие ввиду разрозненности антиправительственных сил сколь-нибудь стоящей оппозииии. До середины 1920-х г2. пангерманцы активно поддерживали антиправительственные выступления, но позже стремились добиватьсл поставленных иелей легитимным путем, так как попытки насильственных переворотов не имели успеха. В связи с этим ими были сформулированы конщепщии государственного переустройства, пропаганда которых должна была сплотить немеикое общество вокруг Пангерманского союза.
\end{abstract}

Ключевые слова: Пангерманский союз, пангерманизм, Бамбергская декларачия, начионал-соииализм, фрайкоры, диктатура, Веймарскал республика, парламентаризм, Ноябрьская революиия, «Пивной путч».

Review. This article addresses the Pan-Germanic concepts of state power and structure in Germany after the November revolution of 1918. The leaders of the Pan-German league (H. Class, L. von Vietinghoff-Scheel, A. Müller) based their vision of the necessary government restructuring on the principle of dictatorship. The idea of dictatorship was tied by some with the sole rule of a leader (Class), by others - by popular representation, chosen from the number of the "true" patriots of Germany (Vietinghoff-Scheel). The author underlines the continuity between Pan-Germanism and National socialism. In the history of Pan-Germanism the Weimar period is of particular importance. This is due to the fact that during the period of Weimar parliamentary democracy the supporters of Pan-Germanism developed significant changes in their views, political thinking, and course of action in the direction of their radicalisation. Despite the sharpness of their statements against government authorities, Pan-Germanists were forced to admit the real political power of these authorities, as well as the absence of a united opposition front due to the fragmentation of the antigovernment forces. Until the middle of the 1920s the Pan-Germanists actively supported antigovernment speeches, but later sought to achieve their goals through legitimate means, as their attempts of violent coups were not successful. Because of this they formulated concepts of political reorganisation, the propaganda of which aimed to unite German society around the Pan-German league.

Key words: Weimar republic, dictatorship, Freikorps, national socialism, Bamberg declaration, Pan-Germanism, PanGerman league, parliamentarism, November revolution, «Beer Putsch».

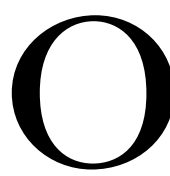

кончание Первой мировой войны и подписание Версальского договора были восприняты частью немецкого общества не как результат прямого военного поражения, а - метафорически - в духе «легенды об ударе в спину» (Dolchstoßlegende). Все выглядело так, как будто бы немцы сами способствовали поражению Германии. На страни- 


\section{История государства и права}

DOI: $10.7256 / 2222-1972.2015 .3 .16511$

цах многочисленных периодических изданий все чаще появляются статьи о «болезни народного тела и духа», «ответственности руководства», «врагах и предателях народа». Большую роль в послевоенной пропаганде сыграл Пангерманский союз, который не просто сохранил свое влияние в качестве оплота политических амбиций «старой империи», но и получил в Веймарском государстве новые возможности. Если до революции 1918 г. союзу сложно было противостоять монархическим институтам и порядку, созданному Бисмарком, то в условиях формирующейся новой государственности возможность образования внушительной оппозиции, хотя бы с точки зрения эффективной пропаганды, казалась уже не столь далекой.

\section{Пангерманский союз}

Пангерманский союз, возникший в 1891 г. и просуществовавший вплоть до 1939 г., представлял собой консервативную, националистическую организацию, основанную на идеях борьбы за «жизненное пространство», защиты и пропаганды немецких интересов, «места под солнцем» и сохранения за Германией статуса великой колониальной державы. Главная резиденция Пангерманского союза размещалась в Берлине, куда после Ноябрьской революции она была перенесена из Майнца (Lützowufer, 5. Berlin), а по стране действовали его многочисленные филиалы. В соответствии с программными положениями Пангерманский союз не являлся политической партией - отчасти из-за невозможности объединить разрозненные националистические движения и ассоциации, имевшие конкретные взгляды и интересы. Партии, по мнению лидера пангерманцев Г. Класса, представляли собой инструмент государства, в то время как надгосударственное движение пангерманизма гораздо шире. Для Класса важно было не ограничивать Пангерманский союз интересами конкретной группы. Он стремился к тому, чтобы союз оставался массовой организацией, т. н. движением национальной оппозиции [17, 3].

Фактической целью деятельности пангерманцев было лоббирование интересов крупных промышленных и финансовых корпораций, что при содействии интеллектуалов из академической среды выразилось в идее «борьбы за германство» (Kampfumdas Deutschtum).

Авторы «Словаря основных исторических понятий» указывают на эволюцию понятия
«Deutschtum» («немецкость»): свой первоначальный структурный смысл понятие приобретает в XIX в., практически сразу после прекращения существования Священной Римской империи германской нации (1806). Он связывается со специфическим «засвидетельствованием и отграничением себя именно как “немецкого народа” от группы европейских народов» [4, 336]. Речь, конечно же, шла о многочисленных немецких государствах, образовавшихся сразу после распада империи, для которых понятие «Deutschtum», объединившее культурную и языковую традицию, выступало «в качестве обруча, скрепляющего их» $[4,336]$. Несколько меняется смысл понятия после 1871 г., когда в обществе возникают представления о недостроенности национального государства, образованного «в форме договоренности монархов, то есть сверху, а не в результате многолетних усилий немецкого национального движения» [4, 654-655]. Даже в тексте Конституции Германской империи 1871 г. речь идет не просто о Германии, а о «всей Германии», включавшей в себя далеко не все области расселения немцев в Центральной Европе, а области на «севере, востоке и западе, жители которых - датчане, поляки, эльзасцы и лотарингцы - либо в этноязыковом, либо в политическом отношении причисляли себя к другим национальностям, которые против своей воли были включены в состав империи» [4, 655].

Пангерманцы, представляющие националистический, оппозиционный фронт, в большей степени были заинтересованы в поиске общественной платформы, национальной идеи, способной сплотить немцев неполитическими методами. Идея «борьбы за германство» позволила в полной мере сплотить националистически настроенную часть немецкого общества вокруг Пангерманского союза, т. к. пангерманцы, особенно в годы Первой мировой войны, развили свою деятельность в духе отвоевания для «германства» необходимого пространства. Здесь они во многом апеллировали к «Политической географии» Ф. Ратцеля или «Геополитике» К. Хаусхофера. Поражение в войне Германии заставило пангерманцев пересмотреть концепцию «германства». Акцент снова был поставлен на противовесе правительству и формировании оппозиционного национального фронта. Агитация Пангерманского союза после войны стала выстраиваться вокруг идеи предательства и биогенетической неполноценности «германства». К языку и культуре, прежде составлявшим 


\section{Исторический журнал: научные исследования № 3 (27) • 2015}

\section{DOI: $10.7256 / 2222-1972.2015 .3 .16511$}

суть «германства», позже дополненного идеей «пространства», теперь добавляется идея поиска «врага» внутри германства, ответственного за военное поражение. Таким врагом для пангерманцев, позволившим им удержать определенный вес в годы Веймарской республики, стал образ врага-еврея. Этому во многом способствовал климат послевоенного немецкого общества, благоприятствовавший пангерманцам, и «конъюнктура этнонационального мышления», т. к. в его основе лежала «не общая государственность, а принадлежность к этнической общности» $[1,266]$.

\section{Деятельность пангерманцев в первые годы Веймарской республики}

В истории пангерманизма веймарский период занимает важное место. Это связано с тем, что в эпоху Веймарской парламентской демократии во взглядах, политическом мышлении и характере действий пангерманцев произошли важные изменения, направленные в сторону их радикализации. Если до 1918 г. пангерманцы были известны благодаря критике конституционной монархии и соответствующих ей государственных реформ, то после Ноябрьской революции они и вовсе занимают радикальную политическую позицию, подчеркивая на страницах многочисленных периодических изданий «ненемецкий» характер парламентской демократии. Демократически избранное народное представительство лидер пангерманцев Генрих Класс называл «сборищем убогих и недобросовестных» $[14,584]$. В демократии другой авторитетный пангерманец, историк Георг фон Белов, усматривал «большую опасность времени, т. к. она была способна поглотить и уничтожить немецкий народ» $[13,40]$.

Несмотря на резкость высказываний в адрес органов государственной власти, пангерманцы вынуждены были признать за ними реальную политическую власть, как и отсутствие ввиду разрозненности антиправительственных сил сколь-нибудь стоящей оппозиции. Настроенные решительно пангерманцы стремились объединить разрозненные оппозиционные силы, связав старые национально-радикальные группировки, существовавшие еще в период «вильгельмистской» монархии, с новыми, основанными на фолькшистской расовой идеологии, националистическими массовыми объединениями. Интеграция оппозиционных сил должна была произойти на почве пангерманизма.
Американский историк Б. Джекиш возлагает на пангерманцев ответственность за консолидацию оппозиции после 1918 г. на национальной, региональной и локальной основах [20]. Пангерманский союз сыграл важную роль в объединении правоконсервативных и радикальнонационалистических сил в период Веймара, а также во многом подготовил почву для последующего захвата власти нацистами.

Поскольку в историографии мало изучен вопрос об активизации политической деятельности Пангерманского союза в первые годы Веймарской республики, можно предположить, что очередной вехой в его истории стала Бамбергская декларация 16 февраля 1919 г. (Bamberger Erklärung), составленная и принятая практически сразу после Ноябрьской революции. В ней лидер пангерманцев Класс фактически обосновал политический курс, исходя из идеи реформирования союза по принципу четкой вертикали власти во главе с «фюрером».

Декларация обличала «бессовестных предателей немецкого народа» и «нерешительность имперских правительств», которые допустили поражение Германии в войне и последующий государственный переворот: «Позор, что персоны, которые сегодня занимают ответственные посты, утверждают и доказывают в силу собственного понимания исторического процесса, что Германия виновата в развязывании войны <..> Не разделяя такой подход, мы тем не менее осуждаем те намерения, которые связаны с насаждением комплекса вины Германии за развязывание войны. Это вовсе не является историческим фактом, ибо наши главные враги Англия, Франция и Россия последовательно и планомерно готовили войну. Они с самого начала вынашивали план уничтожения нашего Отечества...» $[15,260]$.

Основные положения декларации, несмотря на их претенциозность, в меньшей степени затронули структуру самого союза (накануне Классом уже была проведена реформа), а напротив, в большей степени были ориентированы на внешнюю деятельность по радикализации общественного мнения. В декларации провозглашалась необходимость восстановления империи, восстановления армии и флота, возвращения утраченных территорий и многое другое, что летом того же года найдет отражение в статьях Версальского договора. Декларация призывала к немедленной мобилизации немцев против навязывания им условий мира $[19,144]$. Моти- 


\section{История государства и права}

DOI: 10.7256/2222-1972.2015.3.16511

вом к мобилизации, по мнению пангерманцев, стал образ врага-еврея, причастного к поражению Германии [5, 382f.; 6, 197f., 205, 253f., 381f., 402f., 429f.; 7, 251, 253]. В декларации практически впервые публично и полностью был представлен т. н. арийский параграф национал-социалистов, который в будущем стал \$3 «Закона о восстановлении чиновничества» (Gesetzzur Wiederherstellung des Berufsbeamtentums, 1933). Так пангерманцы впервые публично высказались об антисемитизме.

О быстро набиравшем темпе антисемитизме и решительной настойчивости пангерманцев в этом вопросе свидетельствует тот факт, что уже на съезде в Бамберге (1919) по инициативе Класса и Гебзаттеля был учрежден Немецкий союз обороны и наступления (Deutsche Schutz und Trutzbund). Официально это было связано с программными целями Пангерманского союза о заботе и охране немецких интересов, сопряженными с сохранением «немецкого самосознания и немецкой гордости» $[12,5]$. Так, при содействии пангерманцев была учреждена первая массовая и оппозиционная Веймарской республике организация, численный состав которой с 1919 по 1922 г. достиг около 170000 членов [19, 145]. Она объединила разрозненные группы и партии антисемитского толка. Ее руководителями стали заместитель председателя Пангерманского союза барон Константин фон Гебзаттель, Гертцлаф фон Херцберг-Лоттин и Альфред Рот [21, 562].

Не менее важным достижением Бамбергской декларации стало то, что основные линии пропаганды Пангерманского союза в периодической печати перманентно стали выстраиваться на идее вождизма и диктатуры. Пангерманский союз из элитарного клуба немецких имперских интеллектуалов в первые годы Веймара начинает превращаться в массовую организацию, ставящую своей задачей политическую мобилизацию консервативных и радикальных политических сил. При этом возрастает и роль самого Класса. В периодической печати Союз все чаще начинают персонифицировать с его лидером: «Класс и его коллеги», «Класс и его ассоциация», «Класс руководитель союза»и т. д.

На основе анализа активности Пангерманского союза сразу после перемещения штабквартиры в Берлин (1918) можно предположить, что в первые месяцы 1919 г. пангерманцами делались попытки активного вмешательства в систему государственного управления. И хотя в ходе революционных событий с 9 ноября по
1 февраля 1919 г. многие филиалы союза фактически оставались без руководителей, не проявляя политической активности, Класс готовил план решительных действий: «Выдержать момент является для нас делом чести» $[11,258]$.

Свою активность союз проявил уже в первые месяцы 1919 г, поддержав отряды фрайкора (нем. Freikorps - «добровольческий корпус») против коммунистов и левых социал-демократов, стремящихся утвердить советскую власть (январское восстание спартаковцев) в Берлине и Мюнхене. К Капповскому путчу и Рурскому восстанию 1920 г. пангерманцы отнеслись отстраненно, так как Класс считал переворот заведомо плохо подготовленным. Об этом свидетельствует его переписка с генералом Вальтером Люттвицем о финансовой помощи. Класс опасался возможных последствий для Пангерманского союза в связи с провалом переворота. После путча 1920 г. Класс предпочел держаться на расстоянии с Каппом и Люттвицем. В его глазах неудавшийся путч стал «преступлением национального масштаба» $[19,146]$. Но при явном, открытом безразличии и даже критике путча Класс тайно финансировал побег из тюрьмы причастного к нему офицера Германа Эрхардта, бывшего командира фрайкора и в последующем основателя террористической организации «Консул».

К мюнхенскому путчу 8-9 ноября 1923 г. («Пивной путч») Класс отнесся внешне весьма отстраненно. Еще несколькими годами ранее пангерманцы активно поддерживали национал-социалистов, чему способствовали личные дружественные связи Класса и Гитлера. Все изменилось в 1923 г., когда Гитлер и Людендорф попытались публично обвинить Класса в суде [22, 197-199; 10, 18f.]. Речь шла о покушении национал-социалистов на генерала фон Секта, который помешал им установить в Баварии диктатуру. Нуждаясь в союзниках, Гитлер обратился к Классу за помощью, которую тот не спешил предоставить. Зная о готовящемся путче и желании Гитлера его возглавить, Класс начал вести переговоры с лидерами баварского триумвирата - генеральным комиссаром Баварии Густавом фон Каром, генералом Отто фон Лоссовым и полковником баварской полиции Гансом Зайссером. Эти кандидаты, по мнению Класса, обладали реальными возможностями организовать восстание - в отличие от Гитлера. В переписке с лидерами баварского триумвирата Класс убеждал каждого из них организовать «Марш на Берлин» (по аналогии с «Маршем на Рим» Муссоли- 


\section{Исторический журнал: научные исследования № 3 (27) • 2015}

\section{DOI: $10.7256 / 2222-1972.2015 .3 .16511$}

ни в 1922 г.) и учредить в стране национальную диктатуру [22, 197]. Гитлер также вел переговоры с баварцами, но его попытки приобщить триумвират к путчу во главе с самим собой терпят неудачу, в то время как Классу, напротив, удается наладить с ними контакт: «Никакая из групп, которые тогда вооружались для марша на Берлин, вовсе не думала о том, как она возьмет ту самую власть в свои руки. Лишь Пангерманский союз, руководителя которого тогда беспокоило образование единого фронта национально-революционных групп, поддержал начинания группы фон Кара, Лоссова и Зайссера, планировавшей установление в стране верховной диктатуры с последующим переходом к монархии» [10]. И те и другие, вероятно, были настолько уверены в успехе предстоящей акции и собственных силах, что так и не смогли договориться. И поскольку в дальнейшем согласия между оппозиционными, антиправительственными группами в Баварии так и не было достигнуто, совместно организованный путч заведомо был обречен на неудачу. Отчаянные попытки Гитлера все-таки выступить захлебнулись. После провала путча отношения Гитлера с Классом стали довольно напряженными - вплоть до того, что на судебном процессе он обвинил лидера пангерманцев в покушении на фон Секта.

Генерал Ханс фон Сект (1866-1936) во время ноябрьских событий в Мюнхене обладал всеми чрезвычайными полномочиями, которыми наделил его президент республики, когда ситуация, известная как «Пивной путч», стала выходить из-под контроля. На это короткое время, когда «судьба Веймарской республики действительно висела на волоске», генерал фон Сект был фактическим диктатором в стране. По этому поводу пангерманец Класс, связывавший надежды на новый переворот и последующее установление диктатуры с именем фон Секта, направил ему письмо, в котором предложил сыграть роль генерала Монка и восстановить монархию в Германии. Однако фон Сект отказался, оставшись верным своим республиканским конституционным взглядам и убеждениям [22, 197].

Когда «Пивной путч» был подавлен, некоторые сторонники Гитлера погибли, а национал-социалистическая партия была объявлена вне закона. По этому поводу национал-социалистические фанатики планировали покушение на фон Секта, намереваясь «застрелить его во время утренней прогулки верхом». Заговор был раскрыт, а по делу началось следствие. Несмотря на раскрытие заговора во время суда над участниками путча и непричастность Класса, Гитлер, получив возможность свести счеты с лидером пангерманцев, стремился обвинить его и тем самым отвести подозрение от себя, т. к. Класс проходил как свидетель [2, 234]. Суд над организаторами и участниками путча начался в феврале 1924 г. По словам Э. Гумбеля, он превратился в комедию, когда сами «обвиняемые стали руководителями судопроизводства. Они сами определяют, когда выдворить публику из зала. Через своих доверенных лиц они организовали выдачу входных билетов, чтобы их рассчитанная на привлечение избирателей пропаганда получила нужный резонанс. Гитлер энергично подвергает свидетелей допросу, и публика награждает его громкими аплодисментами» [3].

Кроме более или менее организованных акций с целью вмешательства в систему управления страной пангерманцы были замешаны в серии террористических актов. Так, член Пангерманского союза и с 1924 по 1933 г. депутат рейхстага от Немецкой национальной народной партии $(D N V P)$ барон Аксель фон ФрайтагЛорингхофен организовал заговор в Силезии, в котором принимали участие тайные террористические организации «Консул» и «Организация Георга Эшериха». Пангерманцы одновременно были членами националистической и антидемократической конфедерации Соединенных отечественных союзов Германии (Vereinigten Vaterländischen Verbände Deutschlands. VVVD), стремящейся упразднить республику и установить диктатуру [16, 316-321]. Другой пример. Учрежденный по инициативе Класса и Гебзаттеля Немецкий союз обороны и наступления был замешан в 1922 г. в убийстве рейхсканцлера Вальтера Ратенау.

С середины 1920-х гг. пангерманцы стремились добиваться поставленных целей легитимным путем, т. к. попытки насильственных переворотов не имели успеха. По мнению А. Шильдта, после неудачного Капповского путча стало очевидным, что попытки переворота военными методами не находили поддержки у большинства населения [24, 35].

Финансовое положение Пангерманского союза в годы Веймарской республики также было достаточно противоречивым. Союз существовал в основном за счет добровольных пожертвований и членских взносов. В связи с ростом инфляции в 1921-1922 гг. и в период гиперинфляции 1923-1924 гг. руководство союза 
История государства и права

DOI: $10.7256 / 2222-1972.2015 .3 .16511$

настаивало на стопроцентной выплате членских взносов [8, 50f., 65; 9, 82]. На страницах «Alldeutschen Blätter» Класс настойчиво обращал внимание немцев на трудности финансового положения Пангерманского союза. Сложности материального положения усиливались сокращением численного состава. Количество членов союза к 1932 г. сократилось до 10 тыс. человек $[18,13]$.

Со второй половины 1920-х гг. пангерманцы концептуально формулируют свои идеи относительно государственного устройства. Если опыт предыдущих лет наглядно демонстрировал их критику и неприятие республики, а также попытки ее насильственного свержения, то теперь теоретические конструкции пангерманцев начинают выстраиваться вокруг идеи переустройства государства на принципах диктатуры. По мнению Р. Херинга, у пангерманцев существовало как минимум три концепции диктаторского государства [19, 355-379].

\section{Концепции пангерманцев}

Генрих Класс (1968-1953). На основании речей Класса и переписки с коллегами из Мюнхенского и Дрезденского филиалов Пангерманского союза, авторских статей в «Alldeutsche Blätter» и труда «Если бы я был императором» его взгляды на государство диктатуры можно выстроить вокруг следующих тезисов.

Критика парламентаризма. Поскольку парламентаризм рождает коррупцию, а обществу требуется мобилизовать свои ресурсы, чтобы восстановить утраченное могущество страны после войны, то на время, возможно надолго, необходимо запретить партии. При республиканизме все важные для народа решения принимаются коллективно и долговременно. Имеют место торг и коррупция. При диктатуре, по сути, все общественные полномочия принадлежат небольшой группе людей, которые по своему усмотрению, желанию и разумению управляют страной. Парламентаризм ослабляет немецкий народ. По мнению Класса, общество должно быть подготовлено к диктатуре, а мысль о ней должна внедряться гомеопатическими малыми дозами.

Диктатор. Во главе государства должен находиться диктатор. Диктатор должен выбираться на местах из военных и патриотов - членов местных патриотических объединений. Из числа местных диктаторов выбирается один на всю страну, который формирует свой каби- нет. Патриотические объединения и рейхсвер должны вручить власть диктатору, обеспечив ее дальнейшей поддержкой. Ландтаги должны быть распущены. Немецкое право должно прийти на смену римскому праву. Смертная казнь должна быть введена за малейшие нарушение общественной безопасности: забастовки, саботаж и подрыв трудовой дисциплины. Пропаганда пьянства и преступность должны пресекаться и наказываться. Обязательное школьное обучение должно включать изучение закона божьего, библии, катехизиса, за исключением Ветхого завета, а также систематические занятия молодежи спортом [19, 357]. В своей власти диктатор должен опираться на «аристократов не по факту рождения, а успешных, имеющих благородные помыслы, ясное сознание, самоотверженность в поступках и заботе о народе и государстве» $[9,152]$. В вопросе о диктатуре не стоит поворачиваться к прошлому и искать вразумительный пример в истории империи, не стоит также ориентироваться на другие страны (как полагал Трейчке), это есть «судьбоносная задача немецкого народа - осмыслить и ответить на вопросы о собственном будущем» $[9,154]$.

В 1925 г. Класс действительно доработал свою концепцию, опубликовав под псевдонимом Даниэля Фримана эссе «Если бы я был императором» [17, 210f., 221f.]. Класс призвал народ сплотиться вокруг фигуры диктатора и выступить против общего врага, которому демократический режим (коррупция, расшатанное правосознание, испорченные нравы, разорение государства) создал все условия для нормальной жизни, виновника всех бед немцев - еврея [17, 208f.]. Принцип реформ диктатора: «Германия немцам, здоровые немцы - вечности» [17, 222]. Класс, выступая против демократии, исходил из того, что задача установления нового порядка диктатуры - это задача мужчин, «которые не только словами способны критиковать парламентаризм, но и в случае чего доказать это на деле». Однако после Ноябрьской революции в связи с необходимостью расширения социальной базы союза в него стали приглашать женщин и молодежь. Более того, Класс планирует организовать пангерманское женское и молодежное движение в стране [6, 310].

Леопольд фон Фитингхоф-Шеель (18671946). Рассматривал форму правления как смешанную, состоящую из института монархии и народного представительства. Народное (фолькшистское) представительство должно было со- 


\section{Исторический журнал: научные исследования № 3 (27) • 2015}

\section{DOI: $10.7256 / 2222-1972.2015 .3 .16511$}

стоять из лучших представителей. Для этого он настаивал на сохранении парламента с абсолютной законодательной властью, но парламента, состоящего только из патриотов. Он понимал народ не механически, а связывал это понятие с понятием крови. Расизм и антисемитизм представляли собой лейтмотивы его концепции. Первая мировая война понималась им как расовая война, и велась она с целью уничтожения северной, нордической расы. Для этой цели враги-евреи образовали свои государства.

Задачей Пангерманского союза стало образование аналогичного «дома для всех немцев в Центральной Европе, основанного на традиционном укладе немцев» $[9,150]$. В эссе «Размышления о сущности и строительстве фолькшистского государства» (1924), переработанном им же в 1933 г., фон Шеель полагает, что республиканская форма правления исходит из специфического смешения рас как варианта их комфортного сосуществования. Это несет в себе «опасность порабощения одних рас другими» $[19,366]$. Немецкое государство - это не пространство для рас, которые вынуждены к нему приспосабливаться, а народное тело, состоящее из элементов, по жилам которых течет общая немецкая кровь [25]. Он смешал организационную теорию государства и расовую идеологию. В «тело государства» должны быть включены области в Европе с преобладающим немецким населением. Чтобы тело нормально развивалось, его надо сначала очистить от чужеродных элементов.

Государственный порядок выстраивался по принципу разделения и самоуправления всех основных сфер общественной жизни - политики, экономики и культуры. Так, в экономике все территории должны быть разделены на производственные округа, районы и города. Во главе всей экономической сферы должен находиться Имперский хозяйственный съезд (Reichswirtschaftstag). Экономический порядок должен быть освобожден от любых бюрократических препон. В сфере культуры должен преобладать аналогичный уклад - с разницей лишь в том, что культура должна замыкаться границами земель, так, как это было в прошлом. Это было необходимо, чтобы сохранить региональную немецкую культурную специфику, но школьные порядки, которые затрагивали вопросы обучения и воспитания молодого поколения, должны были быть общими - закон, который не был принят в период Веймарской республики. Народные университеты должны были готовить каждого к тому, чтобы стать руководителем, заботясь как о высшем профессиональном, так и о высоконравственном духовном развитии. Субъектами политики должны быть только чистокровные немцы, участвующие в работе рейхстага, решения которого принимались простым большинством голосов. Ответственность за политические решения возлагалась на большинство, из которого выбирались исполнители.

Форма правления - наследственная монархия во главе с императором. Вопрос о фолькшистской диктатуре должен был решаться рейхстагом, а не императором. По сути, император - только духовный лидер.

Артур Мюллер (1883-1957). У него не было законченной программы, а лишь высказывания об основных элементах фолькшистского государства в социальных аспектах. Он считал, что стоит ориентироваться на желания масс. Ему импонировала идеология социализма, но слово «социалистический» он заменил на «социальный». Фолькшистское государство не должно содействовать отдельным личностям и их материальному благополучию, а помочь развивать сразу весь народ от поколения к поколению. Народность - высшая ступень развития общества. Чтобы достичь такого состояния, надо иметь искренние социальные воззрения. Принципы: «общее благо выше частного» и «каждому свое» $[23,6]$.

Әкономическая политика удовлетворяет интересы социальной политики. Экономический уклад исходит из потребностей всего народа. Поэтому надо создать естественную организацию хозяйственной жизни: как и семья - клетка народного тела, так и хозяйственное сообщество - тоже клетка народного тела.

Политические решения принимали хозяйственные руководители, несущие социальную ответственность. Идеал для Мюллера - роман Густава Фрайтага «SollundHaben», описывающий дом немецкого бюргера средней руки, где немецкая добродетель и типичные качества немецкого характера, такие как бережливость, экономность, противопоставляются культуре других народов, прежде всего поляков и евреев. Новому государству требовалась соответствующая система воспитания как для работодателей, так и для самих работников.

Пангерманский союз стал связующим элементом между экстремальным национализмом поздней империи и новыми, фолькшистско-ради- 


\section{История государства и права}

кальными организациями Веймарской республики, сыграв важную роль в дестабилизации первой немецкой демократии. То, что союз продолжил свое существование после крушения монархии и старых порядков, было связано с ухудшением внутреннего положения Германии в период молодой республики, с сохранением фронтовых переживаний целого поколения, представители

\section{Библиография:}

1. Данн О. Нации и национализм в Германии. 1770-1990. СПб.: Наука, 2003. 486 с.

2. Гёрлиц В. Германский Генеральный штаб. История и структура (1657-1945). М.: Центрполиграф, 2005. 478 с.

3. Гумбель Э. Четыре года политических убийств / Пер. с 5-го немецкого издания В. Н. Розанова. М., Пг:: Книга, 1923. 162 с.

4. Словарь основных исторических понятий: Избранные статьи в 2 т. Т. 2 / Пер. с нем. К. Левинсон; сост.: Ю. Зарецкий, К. Левинсон, И. Ширле. М.: Новое литературное обозрение, 2014. 754 с.

5. Alldeutsche Blätter. XXVIII. 1918.

6. Alldeutsche Blätter. XXIX. 1919.

7. Alldeutsche Blätter. XXX. 1920.

8. Alldeutsche Blätter. XXXI. 1921.

9. Alldeutsche Blätter. XXXII. 1922.

10. Alldeutsche Blätter. XXXIV. 1924.

11. Bonhard O. Geschichte des Alldeutschen Verbandes. Leipzig-Berlin: Th. Weicher's Verlag, 1920.291 S.

12. Colsman W. Alldeutschtum und deutsche Kultur. Eine Schicksalsfrage des deutschen Volkes. Leipzig: Th. Weicher' Verlag, 1919. $45 \mathrm{~S}$.

13. Below G., von. Die Wissenschaft der Gegenwart in Selbstdarstellungen // Die Geschichtswissenschaft der Gegenwart in Selbstdarstellungen / Hrsg. von S. Steinberg. Bd. 1. Leipzig, 1925. S. 1-49.

14. Class H. (Einhart). Deutsche Geschichte. Leipzig: Th. Weicher's Verlag, 1912. 426 S.

15. Erklärung des Alldeutschen Verbandes (Bamberger Erklärung) // Geschichte des Alldeutschen Verbandes / Otto Bongard. Anlage 10. Leipzig, 1920. S. 259-269. 15a. Finker K. Vereinigten vaterländischen Verbände Deutschlands (VvVD) 1922-1933/34 // Dieter Fricke [u.a.] (Hrsg.): Lexikon zur Parteiengeschichte. Die bürgerlichen und kleinbürgerlichen Parteien und Verbände in Deutschland (1789-1945). Bd. 4. Köln, 1986. S. 314-321.

16. Class H. (Daniel Frymann). Wenn ich der Kaiser wäre. Politische Wahrheiten und Notwendigkeiten. 5 erweiterte Aufl. Leipzig: Dietrich'schen Verlagsbuchhandlung, 1925. 38 S.

17. Hartwig E. Zur Politik und Entwicklung des Alldeutschen Verbandes von seiner Gründung bis zum Beginn des ersten Weltkrieges (1891-1914). Diss. zur Erlangung des Doktorgrades, masch. Jena, 1966. 354 S.

18. Hering R. Konstruierte Nation. Der Alldeutsche Verband 1890 bis 1939. Hamburg: Hans Christians Verlag, 2003. 600 S.

19. Jackisch B.A. The Pan-German League and Radical Nationalist Politics in Interwar Germany, 1918-1939. Farnham: Burlington (Ashgate Publishing). Surrey, 2012.212 p.

20. Krebs W. Deutschvölkischer Schutz-und Trutzbund (DSTB). 1919-1922/34 // Dieter Fricke [u.a.] (Hrsg.): Lexikon zur Parteiengeschichte. Die bürgerlichen und kleinbürgerlichen Parteien und Verbände in Deutschland (1789-1945). Bd. 4. Köln, 1986. S. 562-568.

21. Kruck A. Geschichte des Alldeutschen Verbandes 1890-1939. Wiesbanden: Franz Steiner Verlag GMBH, 1954. 258 S.

22. Müller A. Der soziale Gehalt des völkischen Gedankens. Berlin, 1925. 16 S.

23. Schildt A. Die Republik von Weimar. Deutschland zwischen Kaiserreich und Drittem Reich (1918-1933). Erfurt, 1997. 182 S.

24. Vietinghoff-Scheel, L. von. Vom Wesen und Aufbau des Voelkischen Staates. Berlin, 1933.112 S.

\section{References (transliterated):}

1. Dann O. Natsii i natsionalizm v Germanii. 1770-1990. SPb.: Nauka, 2003. 486 s.

2. Gerlits V. Germanskii General'nyi shtab. Istoriya i struktura (1657-1945). M.: Tsentrpoligraf, 2005. $478 \mathrm{~s}$.

3. Gumbel' E. Chetyre goda politicheskikh ubiistv / Per. s 5-go nemetskogo izdaniya V. N. Rozanova. M., Pg.: Kniga, 1923.162 s.

4. Slovar' osnovnykh istoricheskikh ponyatii: Izbrannye stat'i v 2 t. T. 2 / Per. s nem. K. Levinson; sost.: Yu. Zaretskii, K. Levinson, I. Shirle. M.: Novoe literaturnoe obozrenie, 2014. $754 \mathrm{~s}$.

5. Alldeutsche Blätter. XXVIII. 1918.

6. Alldeutsche Blätter. XXIX. 1919.

7. Alldeutsche Blätter. XXX. 1920.

8. Alldeutsche Blätter. XXXI. 1921.

9. Alldeutsche Blätter. XXXII. 1922.

10. Alldeutsche Blätter. XXXIV. 1924.

11. Bonhard O. Geschichte des Alldeutschen Verbandes. Leipzig-Berlin: Th. Weicher's Verlag, 1920. 291 S. 


\section{Исторический журнал: научные исследования № 3 (27) • 2015}

DOI: $10.7256 / 2222-1972.2015 .3 .16511$

12. Colsman W. Alldeutschtum und deutsche Kultur. Eine Schicksalsfrage des deutschen Volkes. Leipzig: Th. Weicher’ Verlag, 1919. $45 \mathrm{~S}$.

13. Below G., von. Die Wissenschaft der Gegenwart in Selbstdarstellungen // Die Geschichtswissenschaft der Gegenwart in Selbstdarstellungen / Hrsg. von S. Steinberg. Bd. 1. Leipzig, 1925. S. 1-49.

14. Class H. (Einhart). Deutsche Geschichte. Leipzig: Th. Weicher's Verlag, 1912. 426 S.

15. Erklärung des Alldeutschen Verbandes (Bamberger Erklärung) // Geschichte des Alldeutschen Verbandes / Otto Bongard. Anlage 10. Leipzig, 1920. S. 259-269. 15a. Finker K. Vereinigten vaterländischen Verbände Deutschlands (VvVD) 1922-1933/34 // Dieter Fricke [u.a.] (Hrsg.): Lexikon zur Parteiengeschichte. Die bürgerlichen und kleinbürgerlichen Parteien und Verbände in Deutschland (1789-1945). Bd. 4. Köln, 1986. S. 314-321.

16. Class H. (Daniel Frymann). Wenn ich der Kaiser wäre. Politische Wahrheiten und Notwendigkeiten. 5 erweiterte Aufl. Leipzig: Dietrich'schen Verlagsbuchhandlung, 1925. 38 S.

17. Hartwig E. Zur Politik und Entwicklung des Alldeutschen Verbandes von seiner Gründung bis zum Beginn des ersten Weltkrieges (1891-1914). Diss. zur Erlangung des Doktorgrades, masch. Jena, 1966. 354 S.

18. Hering R. Konstruierte Nation. Der Alldeutsche Verband 1890 bis 1939. Hamburg: Hans Christians Verlag, 2003. 600 S.

19. Jackisch B.A. The Pan-German League and Radical Nationalist Politics in Interwar Germany, 1918-1939. Farnham: Burlington (Ashgate Publishing). Surrey, 2012.212 p.

20. Krebs W. Deutschvölkischer Schutz-und Trutzbund (DSTB). 1919-1922/34 // Dieter Fricke [u.a.] (Hrsg.): Lexikon zur Parteiengeschichte. Die bürgerlichen und kleinbürgerlichen Parteien und Verbände in Deutschland (1789-1945). Bd. 4. Köln, 1986. S. 562-568.

21. Kruck A. Geschichte des Alldeutschen Verbandes 1890-1939. Wiesbanden: Franz Steiner Verlag GMBH, 1954. 258 S.

22. Müller A. Der soziale Gehalt des völkischen Gedankens. Berlin, 1925. 16 S.

23. Schildt A. Die Republik von Weimar. Deutschland zwischen Kaiserreich und Drittem Reich (1918-1933). Erfurt, 1997. 182 S.

24. Vietinghoff-Scheel, L. von. Vom Wesen und Aufbau des Voelkischen Staates. Berlin, 1933. 112 S. 